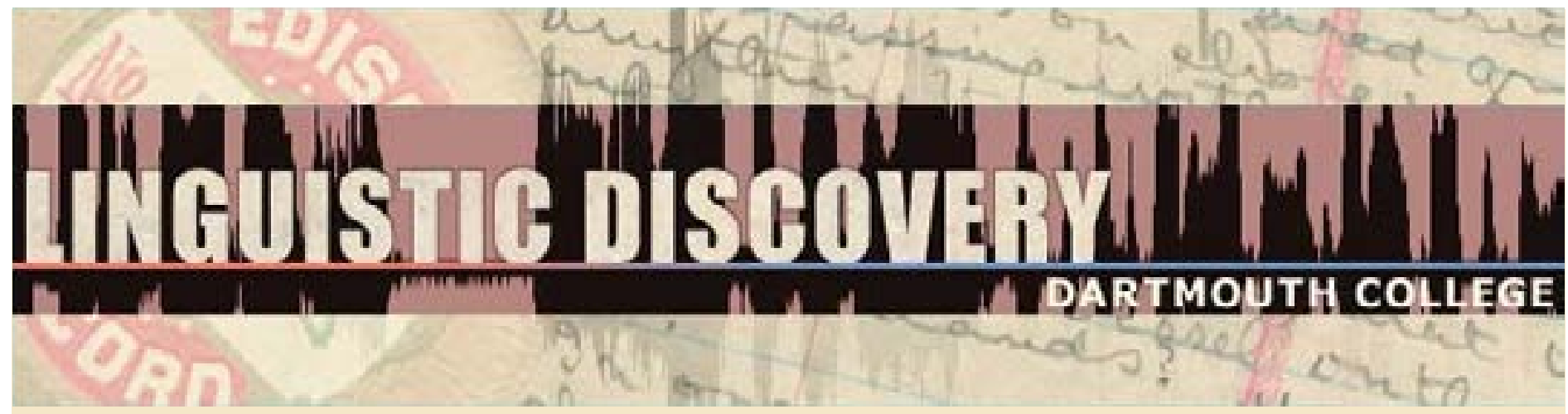

\begin{tabular}{|l|}
\hline Volume 8 \\
Issue 1 \\
2010 \\
\hline
\end{tabular}

\title{
Commentary on Narrog - The Best of Two Maps
}

Sander Lestrade

Radboud University Nijmegen

doi: 10.1349/PS1.1537-0852.A.375

url: http://journals.dartmouth.edu/cgi-bin/WebObjects/ Journals.woa/1/xmlpage/1/article/375

\section{Linguistic Discovery}

Published by the Dartmouth College Library Copyright to this article is held by the authors. ISSN 1537-0852 linguistic-discovery.dartmouth.edu 


\title{
The Best of Two Maps
}

\section{Comment on 'A Diachronic Dimension in Maps of Case Functions' by Heiko Narrog (2010)}

\author{
Sander Lestrade \\ Radboud University Nijmegen
}

Narrog (2010) argues for the addition of a diachronic dimension to semantic maps. He illustrates how this can be accomplished for three different semantic domains: the Instrument-Companion domain, the Source-Agent domain, and the Goal-Recipient domain. Narrog's paper includes a welcome and elaborate overview of the literature on grammaticalization of case marking.

Narrog distinguishes two types of representation of semantic maps: the "classical" map in which distinct connections between meanings can be drawn, and a second type that shows a spatial configuration of meanings or functions (multidimensional scaling (MDS) maps). He argues that addition of a diachronic dimension is only possible for "classical" maps, not for maps illustrating semantic similarity by spatial adjacency. According to Narrog, the factors that make the first type attractive for researchers are the following:

1. They can graphically represent similarity relationships between meanings or functions;

2. they can graphically represent possible versus impossible or, empirically speaking, attested versus non-attested connections between meanings or functions;

3. they can graphically represent information about the directionality in the connections between meanings, and

4. they may contain implicational universals.

In his paper as well as in my present comment, the focus is on the third point. I agree that adding directionality to a relation can make semantic maps more interesting. Unfortunately, the way in which this is done by Narrog (2010) equates all (diachronic) relations. However, the conceptual closeness between different meaning pairs is not always the same. For example, the extension from Source to the temporal domain should not simply be equated with the extension from Source to Instrument. This is precisely what we learn from maps that illustrate similarity by spatial adjacency.

Is it really true that diachronic information "cannot (or only with great difficulty) be represented on statistically plotted maps," as Narrog (2010) argues? I think the answer is no. The merits of the two approaches can and should be combined.

Diachronic information is used to explain synchronic patterns. This diachronic information is only informative when combined with statistical evaluation of the synchronic patterns it serves to explain. Only then the diachronic explanation can be argued to hold cross-linguistically. Without statistical evaluation such as provided by MDS maps, the researcher has to come up with arbitrary threshold values for relations to appear on the map, which is not a satisfactory approach.

A diachronic relation between two meanings will normally only exist if the two meanings are conceptually close to each other. As a result of diachronic meaning extension, two functions might end up with the same form. In MDS maps, the more often two different constructions or 
meanings share a form/construction in different languages, the closer they are plotted together. Therefore, the more often a certain meaning extension took place, the more evidence there is for the similarity of the two meanings involved, and the more evidence for the relevance of the extension itself. Only the relations between meanings or functions that are close to each other on an MDS map are in need of a diachronic explanation. Two functions that coincidentally share a form in one language may not do so in another. These functions will thus not appear close to each other on the cross-linguistic map, and therefore their relation will not call for a diachronic explanation.

Statistical and diachronic information could be combined in two ways. The statistical information can be incorporated into a classical map by manipulating the thickness of the arrow connecting the functions, or one could draw arrows with different lengths on an MDS map. For the latter option, there might be a small drawback: the author of the map cannot manipulate the number of the lines that cross the arrow, something he can easily do in a classical map by arranging the concepts in a convenient and visually pleasing way. That is, the "comparative concepts" (Haspelmath 2008) on a classical map are placed such that the number of crossing lines is kept to a minimum. Since the placement of the concepts on an MDS map is an (opaque) result of the analysis of variance reduced to two dimensions, active manual manipulation is not possible with this kind of maps. However, that will only pose a problem to intelligibility for maps with a very high number of comparative concepts, a situation in which the overall semantic map may not be very telling and the focus should probably be on subdomains anyway.

In sum, I think the addition of diachronic information as proposed by Narrog (2010) is very valuable. This does not have to go at the cost of information about spatial adjacency: the two information types can be combined.

\section{References}

Haspelmath, Martin. 2008. Comparative concepts and descriptive categories in cross-linguistic studies. http://www.eva.mpg.de/ haspelmt/papers.html.

Narrog, Heiko. 2010. A diachronic dimension in maps of case functions. Linguistic Discovery, this issue.

Author's contact information:

Sander Lestrade

Centre for Language Studies

Radboud University Nijmegen

Erasmusplein 1, kamer 9.19

6525 HT Nijmegen

S.Lestrade@let.ru.nl 